\title{
Lithium dynamics in the zeolite-like lithosilicate RUB-29 and its high-temperature structure after dehydration $\left(\mathrm{Cs}_{14} \mathrm{Li}_{42} \mathrm{Si}_{72} \mathrm{O}_{172}\right)$
}

\author{
So-Hyun Park ${ }^{\mathrm{a}, *}$, John B. Parise ${ }^{\mathrm{b}}$, Marion E. Franke ${ }^{\mathrm{c}, 1}$, Tilo Seydel ${ }^{\mathrm{d}}$, Carsten Paulmann ${ }^{\mathrm{e}, \mathrm{f}}$ \\ ${ }^{a}$ Sektion Kristallographie, Department für Geo- und Umweltwissenschaften, Ludwig-Maximilians-Universität München, 80333 München, Germany \\ ${ }^{\mathrm{b}}$ Department of Geosciences, Department of Chemistry and Center for Environmental Molecular Sciences, \\ State University of New York at Stony Brook, NY 11790-2100, USA \\ ${ }^{\mathrm{c}}$ Rheinisch-Westfälische Technische Hochschule Aachen, Institute of Inorganic Chemistry, 52054 Aachen, Germany \\ d Institut Laue-Langevin, 6 rue Jules Horowitz, BP 156, 38042 Grenoble Cedex 9, France \\ ${ }^{\mathrm{e}}$ Mineralogisch-Petrographisches Institut, Universität Hamburg, Grindelallee 48, 20146 Hamburg, Germany \\ ${ }^{\mathrm{f}}$ HASYLAB, DESY, Notkestr. 85, 22603 Hamburg, Germany
}

Received 27 July 2006; received in revised form 13 March 2007; accepted 18 March 2007

Available online 19 April 2007

\begin{abstract}
The thermally induced modifications of the zeolite-like lithosilicate RUB-29 $\left(\mathrm{Cs}_{14} \mathrm{Li}_{24}\left[\mathrm{Li}_{18} \mathrm{Si}_{72} \mathrm{O}_{172}\right] \cdot 14 \mathrm{H}_{2} \mathrm{O}\right.$, space group I222, $a=11.208(1), b=17.286(1), c=23.536(1) \AA$, and $V=4660(1) \AA^{3}$ [S.-H. Park, J.B. Parise, H. Gies, H. Liu, C.P. Grey, B.H. Toby, J. Am. Chem. Soc. 122 (44) (2000) 11023-11024]) have been studied focusing on static and dynamical disorder of Li. After the water loss, dehydrated RUB-29 (HT-d-RUB-29) maintains the basic space group I222 at high temperatures from 473 up to 1073 K. However, the distribution of extra-framework Li and Cs cations in HT-d-RUB-29 became distinctly different from those in the original structure. In particular, extra-framework Li cations located within porous 8- and 10-membered ring-channels, where these Li cations were partially coordinated with zeolitic water in the original structure, migrate into densely packed $\mathrm{Li}_{2} \mathrm{O}$-layers after dehydration. As a result of the migration, the number of empty sites relevant for $\mathrm{Li}$ hopping in $\mathrm{Li}_{2} \mathrm{O}$-layers decreases, which give a negative effect on the long-range charge transfer in dehydrated RUB-29. Its DC conductivity values estimated from AC impedance spectra lie between $2 \times 10^{-5}$ and $6 \times 10^{-5} \mathrm{~S} \mathrm{~cm}^{-1}$ at $873 \mathrm{~K}$, and a low activation energy of $51 \mathrm{~kJ} / \mathrm{mol}(\cong 0.53 \mathrm{eV})$ could be determined for the bulk charge transfer process in dehydrated RUB-29.
\end{abstract}

(C) 2007 Elsevier Inc. All rights reserved.

Keywords: Lithosilicate; RUB-29; Lithium; Conductivity; Dehydration; Zeolite-like

\section{Introduction}

The chemistry of families of zeolite-like silicate materials built with $\left[(\mathrm{T}, \mathrm{Si}) \mathrm{O}_{4}\right]$-tetrahedra ( $\mathrm{T}$ is usually $\left.\mathrm{Al}^{3+}\right)$ has been extended in recent years with the discovery of several synthetic lithosilicates in which $\mathrm{Li}^{+}$act as a "T species" in open silicate frameworks [1-6]. Among these zeolite-like lithosilicates, RUB-29 (Ruhr-Universität-Bochum, phase

\footnotetext{
* Corresponding author. Tel.: +49 89289 14041; fax: +49 8928914015. E-mail address: sohyun.park@lmu.de (S.-H. Park).

${ }^{1}$ Present address: Gesellschaft für Wirtschaftforschung Duisburg GmbH, Forsthausweg 2, 47057 Duisburg, Germany.
}

\# 29): $\mathrm{Cs}_{14} \mathrm{Li}_{24}\left[\mathrm{Li}_{18} \mathrm{Si}_{72} \mathrm{O}_{172}\right] \cdot 14 \mathrm{H}_{2} \mathrm{O}$ is of particular interest because it shows a high degree of Li mobility [1]. In RUB-29, edge- and corner-sharing $\left[\mathrm{LiO}_{4}\right]$-tetrahedra are connected to form so-called layer-like building units (LLBU's) [1,6]. Each pure $\mathrm{Li}_{2} \mathrm{O}$-layer is located in-between $\mathrm{SiO}_{2}$-layers which contain channels with pore openings of 8or 10-membered rings (MRs) of $\left[\mathrm{SiO}_{4}\right]$-tetrahedra (Fig. 1). The characteristic open framework is created by alternating arrangements of single LLBU of $\left[\mathrm{LiO}_{4}\right]$ and that of $\left[\mathrm{SiO}_{4}\right]$ parallel to the crystallographic $c$-axis (Fig. 1). This connection gives rise to two rare secondary building units (SBUs) [7] containing 3-membered rings (3MRs) of framework tetrahedra (so-called ( $\mathrm{Li}, \mathrm{Si}$ )-spiro-5 [1,2] and ( $\mathrm{Li}, \mathrm{Si}$ )-spiro-3, 5 

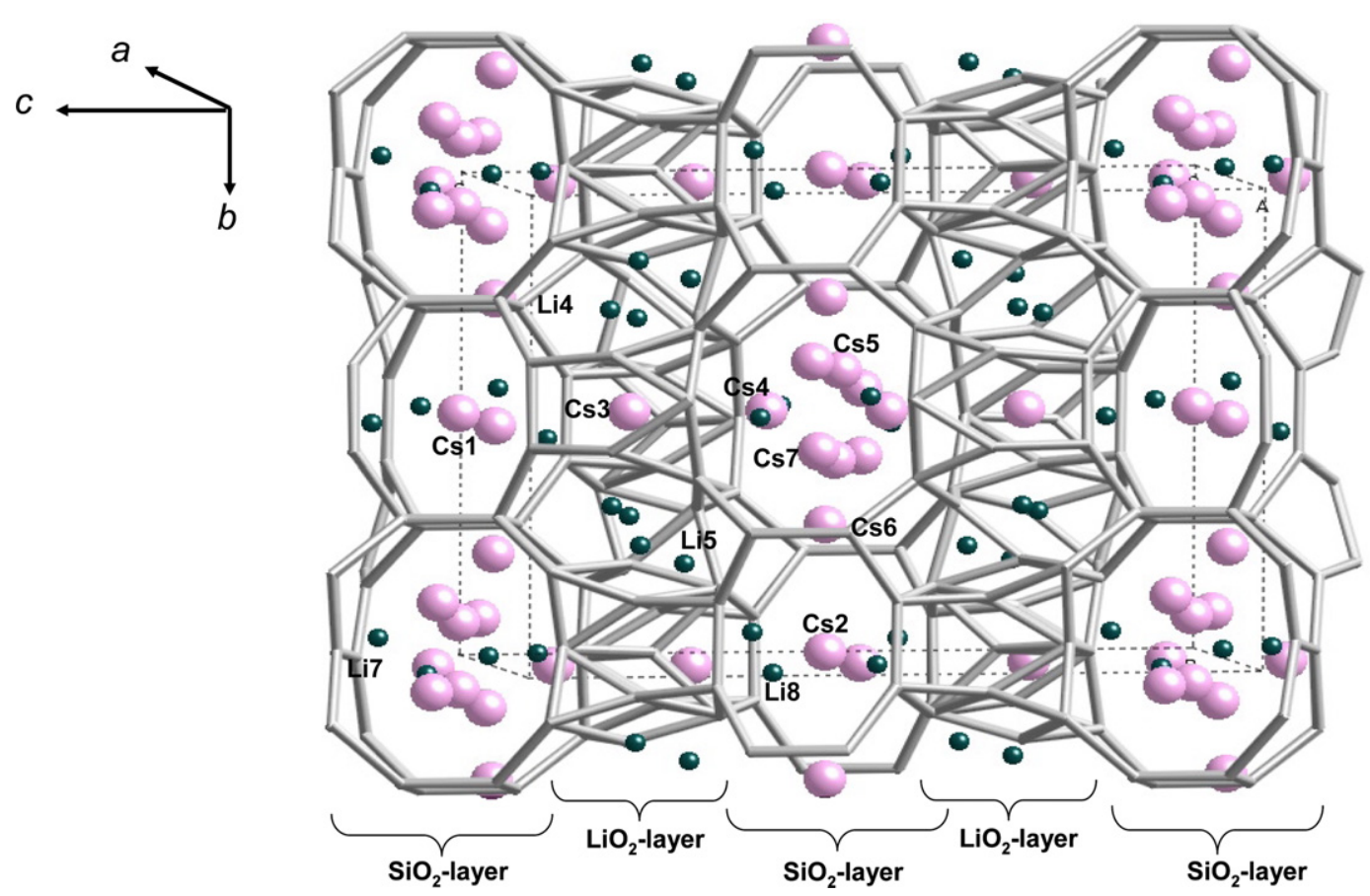

Fig. 1. Distribution of extra-framework $\mathrm{Li}$ and $\mathrm{Cs}$ cations occluded within the framework of $\left[\mathrm{LiO}_{4}\right]$ - and $\left[\mathrm{SiO}_{4}\right]$-tetrahedra in as-synthesized $\mathrm{RUB}-29[1,6]$. For clarity, the framework is represented by sticks joining $\mathrm{Si}$ - and $\mathrm{Li}$-centers of $\mathrm{SiO}_{4}$ and $\mathrm{LiO}_{4}$. The sites Cs3, Cs4, Cs5, Cs6, and Cs7 are available also for water molecules statistically disordered with $\mathrm{Cs}$ cations. In the $\mathrm{Li}_{2} \mathrm{O}$-layers presenting $3 \mathrm{MR}$ 's, $\mathrm{Li}$ cations are apart from each other in two different $\mathrm{Li}-\mathrm{Li}$ distances (about 2.5 and $3.4 \AA$ ). In the $\mathrm{SiO}_{2}$-layers, there is the main pore system of 8-/10MRs-channels.

[1]). From the point of view of crystal chemistry, a high rate of site-exchange has been predicted for Li in RUB-29. This is based on the presence of partially occupied edge-sharing $\left[\mathrm{LiO}_{4}\right]$-tetrahedra within densely packed $\mathrm{Li}_{2} \mathrm{O}$-layers where $\mathrm{Li}$ cations can find shorter pathways for charge transportation (about $2.5 \AA$ ) [6]. This feature is unusual in known Libearing zeolites $[8-10]$. Most Li-exchanged microporous materials contain only extra-framework Li cations far apart from each other in porous cages and channels. Thus the topology of RUB-29, containing closely spaced sites in the $\mathrm{Li}_{2} \mathrm{O}$-layer (Fig. 1), offers a new type for Li conduction in zeolitic materials. In RUB-29, there are also readily ionexchangeable extra-framework Li cations along with disordered Cs cations and water molecules at more separated sites in the 8- and 10-MR channels (Fig. 1). On the whole, at least three types of mechanisms for Li conduction can be considered with RUB-29: through the $\mathrm{Li}_{2} \mathrm{O}$-framework layers; through the channels and pore intersections; through site-exchange processes of $\mathrm{Li}^{+}$hopping between framework and extra-framework sites. This unusual circumstance is unique to RUB-29, and its variations offer a high degree of potential for Li-conductivity tuning by substitution in both framework and extra-framework sites.

Discussion of the cationic conductivity in zeolite-like materials is greatly simplified when they are studied in their dehydrated forms, since water molecules in microporous structures significantly influence the mobility as well as characteristic energies of the metal cations [8-10]. Hydrated cations have a weaker interaction with the negatively charged framework. As a result, the cations can move more readily through the lattice such that the conductivity increases with the degree of hydration.

To investigate the structural basis for the unusual $\mathrm{Li}^{+}$ conductivity properties of dehydrated RUB-29, neutron powder diffraction data were collected at various temperatures. At room temperature they contain a number of weak reflections that cannot be indexed using the basic cell of assynthesized RUB-29 $\left(\boldsymbol{I} 222,11 \times 17 \times 24 \AA^{3}\right)$ [11]. On the basis of crystallographic considerations, the corresponding superstructure can be extremely large, for which an ordering of extra-framework constituents is very likely. In general, structure analysis of such a large superstructure has to deal with serious peak overlap in powder diffraction patterns. At the same time, a much larger number of atomic parameters need to be refined. Even the average structure of RUB-29 is an extremely complex with 46 crystallographically independent sites $[1,6]$. The combined use of synchrotron X-ray single crystal data, to provide a large non-overlapping reflection list, and high-resolution neutron powder diffraction, which is more sensitive to the detection of lithium in presence of cesium, could help in the solution of structural problems displaying non-trivial crystallographic issues such as dynamic and static disorder punctuated by problems of superstructures. We have performed a wide range of measurements at temperatures between 4 and $1073 \mathrm{~K}$, to explore the crystal symmetries adopted by dehydrated RUB-29 in its low- and high-temperature forms (named as LT- and HT-d-RUB-29, respectively, where -d- stands for 'dehydrated'). Analysis with synchrotron single crystal diffraction data collected below 
and at room temperature of dehydrated RUB-29 (LT-dRUB-29 [12]) revealed one-dimensional incommensurably modulated structures in superspace group symmetry I222( $\alpha 00) 000$ [13]. The locations of satellites pairs are almost unchanged with a small increase of $q$-vector from $0.56 a^{*}$ at $120 \mathrm{~K}$ to $0.59 a^{*}$ at $293 \mathrm{~K}$. Unequal intensities of satellite pair and missing superstructure reflections in the $h 0 l$-plane indicate an ordering fashion, which can be induced by occupational fluctuations combined with transverse displacements of atoms parallel to the $b$-axis [14]. Structure analysis of the incommensurately modulated structure of LT-d-RUB-29 is in progress, and details will be reported elsewhere.

The hopping frequencies of various possible Li motions expected in RUB-29 probably cover a wide range from fast and locally limited to slow long-range motions, requiring a combination of techniques like nuclear magnetic resonances (NMR) and quasi-elastic neutron backscattering (QENS) spectroscopy. Such experiments have been carried out. Unfortunately, there is a limited ability of ${ }^{6} \mathrm{Li}$ MAS NMR to resolve isotropic chemical shifts from $\mathrm{Li}$ at several unique crystallographic sites (eight in RUB-29), and/or to resolve fast motions between closely spaced sites. As a complementary tool, quasi-elastic neutron scattering $[15,16]$ was applied in an attempt to probe the fast dynamics in RUB-29 at the instrument IN10A at ILL (Institut Laue-Langevin, Grenoble, France), covering a frequency range of $0.2-2 \mathrm{GHz}$. This investigation is still at an early stage, and no unambiguous conclusions can thus yet be drawn. While a signal indicative of the motion of water molecules in as-synthesized RUB-29 at room temperature could be observed, no evidence of any Li motion could be found in the dehydrated form, either due to a too weak scattering, or due to the motions out of the frequency scale of this instrument. The faster Li motions may be between $\sim 10^{-4} \mathrm{~s}$, based on results of ${ }^{7} \mathrm{Li}$ MAS NMR [1], and $\sim 10^{-9} \mathrm{~s}$, the time scale of QENS at IN10A. Nevertheless, these results and further fixed window measurements point to the change of dynamic in RUB-29 upon dehydration and agree with results from structural analyses. Experimental details of these QENS experiments are given in $[17,18]$. Therefore we concentrate on the true structures of the hightemperature forms of dehydrated RUB-29. The structural changes after dehydration are discussed in relation to the Li dynamics with supporting evidence from AC impedance spectra.

\section{Experimental}

In a typical reaction for synthesizing RUB-29 [1,6], a mixture with a molar composition $1 \mathrm{SiO}_{2}: 0.23 \mathrm{Li}_{2} \mathrm{O}$ : $0.23 \mathrm{Cs}_{2} \mathrm{O}: 0.08 \mathrm{TEAOH}: 40 \mathrm{H}_{2} \mathrm{O}$ was aged for 5 days at room temperature with slow stirring. The resulting highly basic, clear solution was charged into large $120 \mathrm{ml}$ Teflon-lined stainless steel autoclaves (Parr). The reaction vessels were kept in a convection oven at $493 \mathrm{~K}$ for 10 days. The crystalline product contains only RUB- 29 with no impurities. Larger crystals of RUB-29 with an edge length of $80-150 \mu \mathrm{m}$ could be obtained by adding $0.5 \mathrm{~mol}$ of a $40 \% \mathrm{HF}$ solution into the reaction mixture. The milky starting gel was charged into a small $23 \mathrm{ml}$ Teflon-lined autoclave (Parr) and then heated at $473 \mathrm{~K}$ for two weeks. In this case, aggregates of the known microporous lithosilicates RUB-23 [2] coexist with large crystals of RUB-29 in the crystalline product.

The thermal behavior of RUB-29 was characterized by dehydration experiments using time-resolved synchrotron X-ray powder diffraction techniques [19] with a wavelength $\lambda=0.9274 \AA$, determined by using $\mathrm{a} \mathrm{LaB}_{6}$ standard at beam line X7B in the National Synchrotron Light Source at Brookhaven National Laboratory, NY, USA. A powder sample of RUB-29 as-synthesized was packed into a $0.5 \mathrm{~mm}$ silica capillary, and the open end of the capillary was attached to a standard goniometer head in parallel Debye-Scherrer geometry. The rotating capillary was heated by a hot air stream from 293 up to $1273 \mathrm{~K}$ with a ramping rate of $4.1 \mathrm{~K} / \mathrm{min}$. The powder diffraction patterns were continuously recorded behind a $4 \mathrm{~mm}$ wide vertical slit, thereby exposing a slice of an imaging plate-detector translated behind it.

For high-resolution neutron powder diffraction (HRNPD) experiments, it is necessary to eliminate the detrimental effects of incoherent scattering from hydrogen. This was achieved as follows: $2 \mathrm{~g}$ of RUB-29 was dehydrated by charging the sample into a Pyrex-glass tube and mounted on a vacuum line overnight at $473 \mathrm{~K}$. This material was then exposed to heavy water $\left(\mathrm{D}_{2} \mathrm{O}\right)$ vapor for one day. The deuterated sample was again dehydrated at $473 \mathrm{~K}$ in vacuum for about half a day. These $\mathrm{D}_{2} \mathrm{O}$ exchange and dehydration procedures were repeated twice before the glass tube was sealed up in vacuum to avoid rehydration. The data collection was carried out at the timeof-flight instrument HRNPD (High Resolution Neutron Powder Diffractometer) at ISIS, Rutherford Appleton Laboratory, Chilton, UK. For collecting data, the sample of dehydrated RUB-29 was recharged into a vanadium can within a glove box. A series of HRNPD data were measured on three different detectors $\left(154^{\circ}, 90^{\circ}\right.$, and $\left.30^{\circ}\right)$ at 473 and $673 \mathrm{~K}$.

In the preparation for X-ray single crystal diffraction (XSD) experiments, the easily reversible re-hydration in dehydrated zeolitic materials requires consideration. For the present study, it was critical to keep the dehydrated crystal from atmospheric moisture during the experiment. This was achieved by dehydrating in situ during data collection in the following manner: a plate-like single crystal of as-synthesized RUB-29 $\left(80 \times 80 \times 20 \mu \mathrm{m}^{3}\right)$ was affixed with a smear of grease onto the tip of a $0.3 \mathrm{~mm}$ diameter quartz-glass capillary. This was packed into a $0.5 \mathrm{~mm}$ quartz-glass capillary so that the crystal was jammed between the two capillaries without wiggling during the high-temperature measurements. The measurement of XSD data was performed at the instrument F1 at Hamburger Synchrotronstrahlungslabor (HASYLAB) at Deutsches Elektronen-Synchrotron 
(DESY). Intensities were registered with a CCD camera (MAR345, 2k) positioned at $60 \mathrm{~mm}$ from the crystal. Data were collected in $\phi$-scan mode from $1^{\circ}$ to $181^{\circ}$ in steps of $0.5^{\circ}(\Delta \phi)$ with $\lambda=0.7100(3) \AA$ ( $\mathrm{Si}(111)$ monochromator) over a wide range of temperatures using a hot nitrogen gas oven. The data collection was carried out initially with 20-30 snap-shots at constant $\phi\left(=1.0^{\circ}\right.$ and $\left.1.5^{\circ}\right)$ while increasing the temperature from 293 up to $473 \mathrm{~K}$ in order to monitor the dehydration process. Subsequently, high-temperature data were measured at $473,673,873$, and $1073 \mathrm{~K}$. During the measurement at $1073 \mathrm{~K}$, discontinuities of the data were observed, which could be due to phase transitions or decomposition of the sample.

The first AC impedance spectroscopy (IS) measurements with RUB-29 were conducted at laboratories of the Institute of Inorganic Chemistry at Rheinisch-Westfälische Technische Hochschule Aachen (RWTH). The dehydrated material compacted to a pressed pellet (pellet thickness $=0.106 \mathrm{~mm}$, diameter $=5 \mathrm{~mm}$ ) in an argon flooded glove box was placed between plane-parallel platinum electrodes within the high-temperature cell. The complex impedance $Z^{*}(v)$ was recorded in a frequency range $10^{1} \leqslant v \leqslant 10^{7} \mathrm{~Hz}$ and a temperature range between $298 \mathrm{~K}$ and $873 \mathrm{~K}$ at intervals of $10 \mathrm{~K}$ at a nitrogen pressure of $0.2 \mathrm{~Pa}$. IS measurements were carried out with Impedance Analyzer Agilent 4192 A applying an amplitude of $100 \mathrm{mV}$. The second cycle of measurement was performed with identical pellet and setting directly after the first run. The second set of IS data with a pressed pellet (diame- ter $=4 \mathrm{~mm}$ and thickness $=1 \mathrm{~mm}$ ) of RUB-29 was measured at Department für Geosciences at LMU on an impedance analyzer (high-precision Hewlett-Packard LCR-meter 4284A). After the pellet was dehydrated within the measuring cell at $473 \mathrm{~K}$ in nitrogen atmosphere overnight, electrical linearity of the sample response was probed in $2 \mathrm{~V}$. The IS spectra were recorded twice in the frequency range $20-10^{6} \mathrm{~Hz}$ upon heating and cooling between 423 down to $923 \mathrm{~K}$ at intervals of $20 \mathrm{~K}$ in $\mathrm{N}_{2}$ atmosphere.

\section{Results}

\subsection{Dehydration experiments using time-resolved synchrotron $X$-ray powder diffraction}

Fig. 2 shows time-resolved synchrotron X-ray powder diffraction patterns for as-synthesized RUB-29 heated from 293 to $1273 \mathrm{~K}$. The discontinuity occurring between 373 and $473 \mathrm{~K}$ is due to the dehydration of the material. The structure of dehydrated RUB-29 is stable up to the appearance of patterns indicative of a reconstructive phase transition to an unknown phase or decomposition at $1073 \mathrm{~K}$. This in situ dehydration experiment demonstrates the high thermal stability of this open framework structure containing unusual building units of $3 \mathrm{MRs}$ of $\left[\mathrm{LiO}_{4}\right]-$ and $\left[\mathrm{SiO}_{4}\right]-$ tetrahedra. In contrast, other zeolite-like beryllosilicates and zincosilicates containing $3 \mathrm{MRs}$, such as lovdarite [20], gaultite [21], and synthetic zincosilicates VPI-7 $[22,23]$ and RUB-17 [24], are stable only up to $523 \mathrm{~K}$ [22].

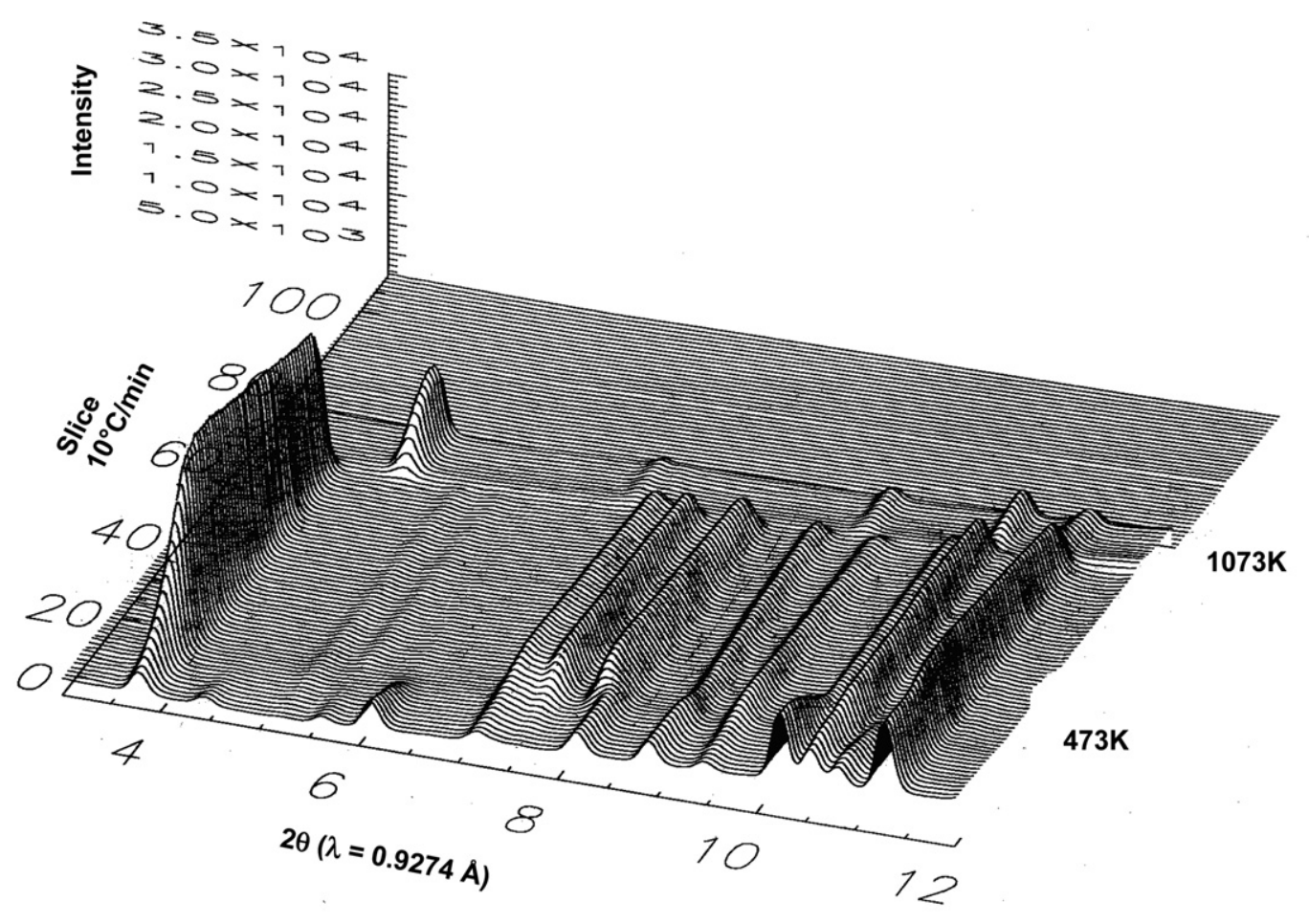

Fig. 2. Time-resolved synchrotron X-ray powder diffraction pattern collected during continuous heating of as-synthesized RUB-29 from 293 to $1273 \mathrm{~K}$. A discontinuity was observed between 373 and $473 \mathrm{~K}$ due to the water loss. After the dehydration, the structure of water-free RUB-29 is stable up to $1073 \mathrm{~K}$, whereupon a reconstructive phase transition or sample decomposition accounts for the second discontinuity. 


\subsection{Synchrotron $X$-ray single crystal diffraction (XSD)}

Each data set was indexed and integrated using the program package XDS [25] and reciprocal lattice planes were reconstructed using the software XCAVATE [26]. Reconstructed reciprocal planes of XSD data collected at 473, 673 , and $873 \mathrm{~K}$ show exclusively main reflections (i.e. no structural modulation) which can be indexed in $\mathbf{I 2 2 2}$ with a cell dimension of approximately $11 \times 17 \times 24 \AA^{3}$, i.e. the basic cell of as-synthesized RUB-29 [1], except for reflections due to a second grain in the RUB-29 sample (Fig. 3). These high-temperature structures of dehydrated RUB-29 are denoted HT-d-RUB-29 $473 \mathrm{~K}, 673 \mathrm{~K}$, and $873 \mathrm{~K}$, respectively. The last data set collected at $1073 \mathrm{~K}$ contained extra reflections of an unknown crystalline phase, which became amorphous after a while at $1073 \mathrm{~K}$. These observations confirm the results from the in situ X-ray powder dehydration experiments (Fig. 2), i.e. that RUB-29 is thermally stable up to $1073 \mathrm{~K}$.

The structures at 473,673 , and $873 \mathrm{~K}$ were solved by direct methods [27]. Initial E-map calculations revealed some sites for framework Si and extra-framework Cs sites. Identification of missing sites and their contents were performed by least squares refinement and difference Fourier synthesis using the program package SHELXL-97 [28]. The site Cs7 determined for Cs disordered with zeolitic water in the original structure of RUB-29 [1] could not be found (Table 1). The structure models obtained were further refined with neutron powder diffraction data for

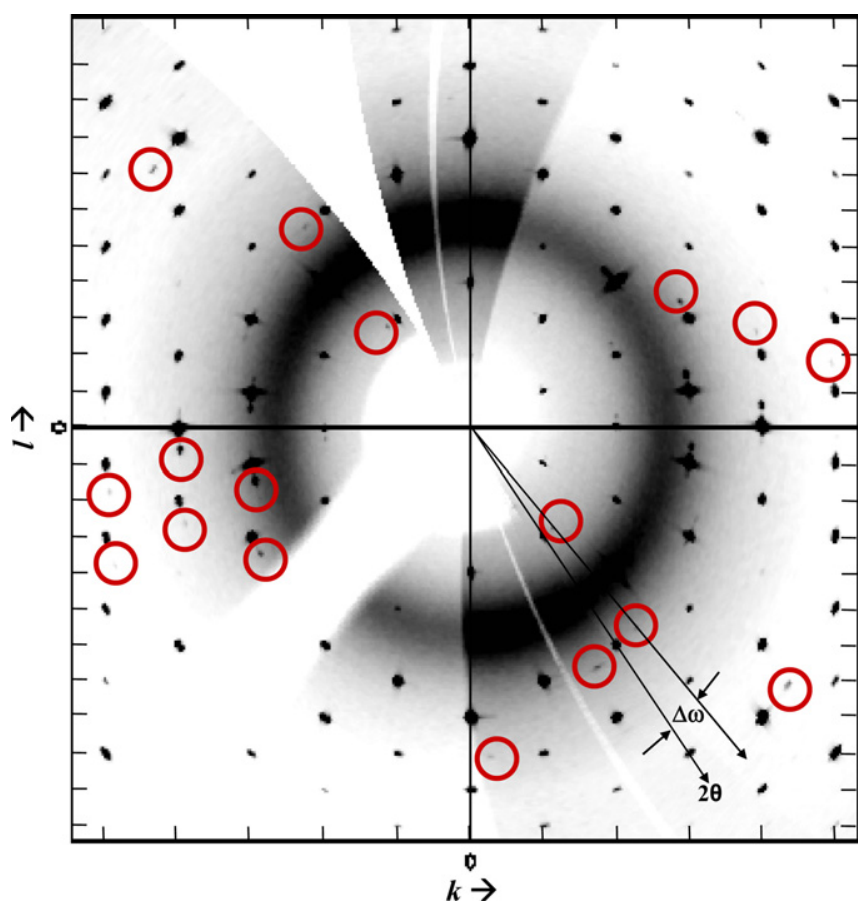

Fig. 3. Reconstructed reciprocal 0kl plane of HT-d-RUB-29_473 K. There are only main reflections that can be indexed in space group $\mathbf{I} 22$. Weak additional reflections (marked in circles) due to a second grain are positioned beside the main reflections at equal $2 \theta$ and at equal $\Delta \omega$.
Table 1

Occupancy parameters of extra-framework cations of dehydrated RUB-29 resulted from structure analysis with XSD data

\begin{tabular}{llllll}
\hline Site name & Atom & Multiplicity & \multicolumn{3}{l}{ Occupancy } \\
\cline { 3 - 6 } & & & $473 \mathrm{~K}$ & $673 \mathrm{~K}$ & $873 \mathrm{~K}$ \\
\hline $\mathrm{Li} 1$ & $\mathrm{Li}$ & 4 & $0.90(4)$ & $0.98(4)$ & $0.94(6)$ \\
$\mathrm{Li} 2$ & $\mathrm{Li}$ & 8 & $1.00(6)$ & $0.89(6)$ & $0.93(7)$ \\
$\mathrm{Li} 3$ & $\mathrm{Li}$ & 8 & $0.86(6)$ & $0.86(6)$ & $0.89(7)$ \\
$\mathrm{Li} 4$ & $\mathrm{Li}$ & 8 & $0.76(3)$ & $0.73(3)$ & $0.72(4)$ \\
Li5 & $\mathrm{Li}$ & 8 & $0.62(6)$ & $0.83(5)$ & $0.93(6)$ \\
Li6 & $\mathrm{Li}$ & 8 & $1.00(6)$ & $0.84(6)$ & $0.68(6)$ \\
Cs1 & $\mathrm{Cs}$ & 2 & $0.98(1)$ & $0.99(1)$ & $1.00(1)$ \\
Cs2 & $\mathrm{Cs}$ & 2 & $0.97(1)$ & $0.94(1)$ & $0.90(1)$ \\
Cs3 & $\mathrm{Cs}$ & 4 & $0.97(1)$ & $0.96(1)$ & $0.95(1)$ \\
Cs4 & $\mathrm{Cs}$ & 4 & $0.17(1)$ & $0.06(1)$ & $0.08(1)$ \\
Cs5 & $\mathrm{Cs}$ & 4 & $0.38(1)$ & $0.46(1)$ & $0.48(2)$ \\
Cs6 & $\mathrm{Cs}$ & 4 & $0.63(2)$ & $0.78(2)$ & $0.80(2)$ \\
\hline
\end{tabular}

several reasons: (1) due to the observation of a second individual in the sample (Fig. 3); (2) the low diffraction range near to $d=3.1 \AA$ was excluded since the Debye-Scherrer rings of both quartz capillaries (Fig. 3) makes it difficult to correctly integrate intensities of HT-d-RUB-29; (3) an analysis with the X-ray data alone is insufficiently sensitive to Li-sites because of the low X-ray scattering cross-section of Li (cf. Section 1). The latter disadvantage of X-ray scattering is aggravated at elevated temperatures.

\subsection{Structure refinements of $H T-d-R U B-29$ with $H R N P D$ data}

Rietveld refinements were carried out using the program package GSAS [29] with the starting models for HT-dRUB-29_473 K and 673 K, derived from XPD data analysis. For fitting three HRNPD profiles measured on three different detectors at each temperature (473 and $673 \mathrm{~K}$ ), zero point, cell parameters and peak-form functions were refined simultaneously. The HRNPD pattern of HT-d-RUB-29 can be indexed within space group $\mathbf{I 2 2 2}$ with $a=11.2058(2)$ and 11.2057(2) $\AA$; $\quad b=17.3085(3)$ and $17.3440(3) \AA ; \quad c=23.6133(4)$ and $23.7658(5) \AA$; $V=4580.0(2)$ and $4618.9(2) \AA^{3}$ at 473 and $673 \mathrm{~K}$, respectively. The lattice normally expands in both $b$ and $c$ directions, but is almost constant with temperature in $a$-direction.

Rietveld refinements included atomic parameters of oxygen, silicon, cesium, and framework and non-framework lithium sites, step-by-step. The framework was geometrically constrained with $d(\mathrm{Si}-\mathrm{O})=1.61 \AA \pm 0.01 \AA$ and $d(\mathrm{Li}-\mathrm{O})=2.0 \AA \pm 0.02 \AA$, as additional information about the lithosilicate framework. Group-specific atomic displacement parameters for all $\mathrm{O}, \mathrm{Si}$, and $\mathrm{Li}$ sites were refined with occupancy $=1$, while those for all Cs sites were initially calculated for the values of occupancies determined from the XSD analysis (Table 1). With these constraints in place, and assuming the oxygen and silicon sites were 
fully occupied, occupancies for the Cs and Li-sites could be refined simultaneously.

In agreement with the XSD analysis, the sites Cs1, Cs2, and Cs3 (Fig. 4a) are fully occupied by Cs cations, whereas Cs4, Cs5, and Cs6 (Fig. 4a-c) show partial occupation. The final stages of Rietveld analysis included simultaneous refinements of atomic parameters for all framework and non-framework constituents with isotropic atomic dis- placements, as well as occupancies of all $\mathrm{Cs}$ and $\mathrm{Li}$ sites. The six different $\mathrm{Li}$ sites (Li1-Li6) located within the $\mathrm{Li}_{2} \mathrm{O}$-layers (Fig. 5) are almost fully occupied by $42 \mathrm{Li}$ atoms within the standard deviations of their occupancies (Tables 2 and 3). Compared to the original structure of as-synthesized RUB-29 (Fig. 1), no extra sites for Li could be found in 8- and 10-MR channels. Furthermore, in agreement with the XSD results, none of $\mathrm{Li}$ and $\mathrm{Cs}$ could be
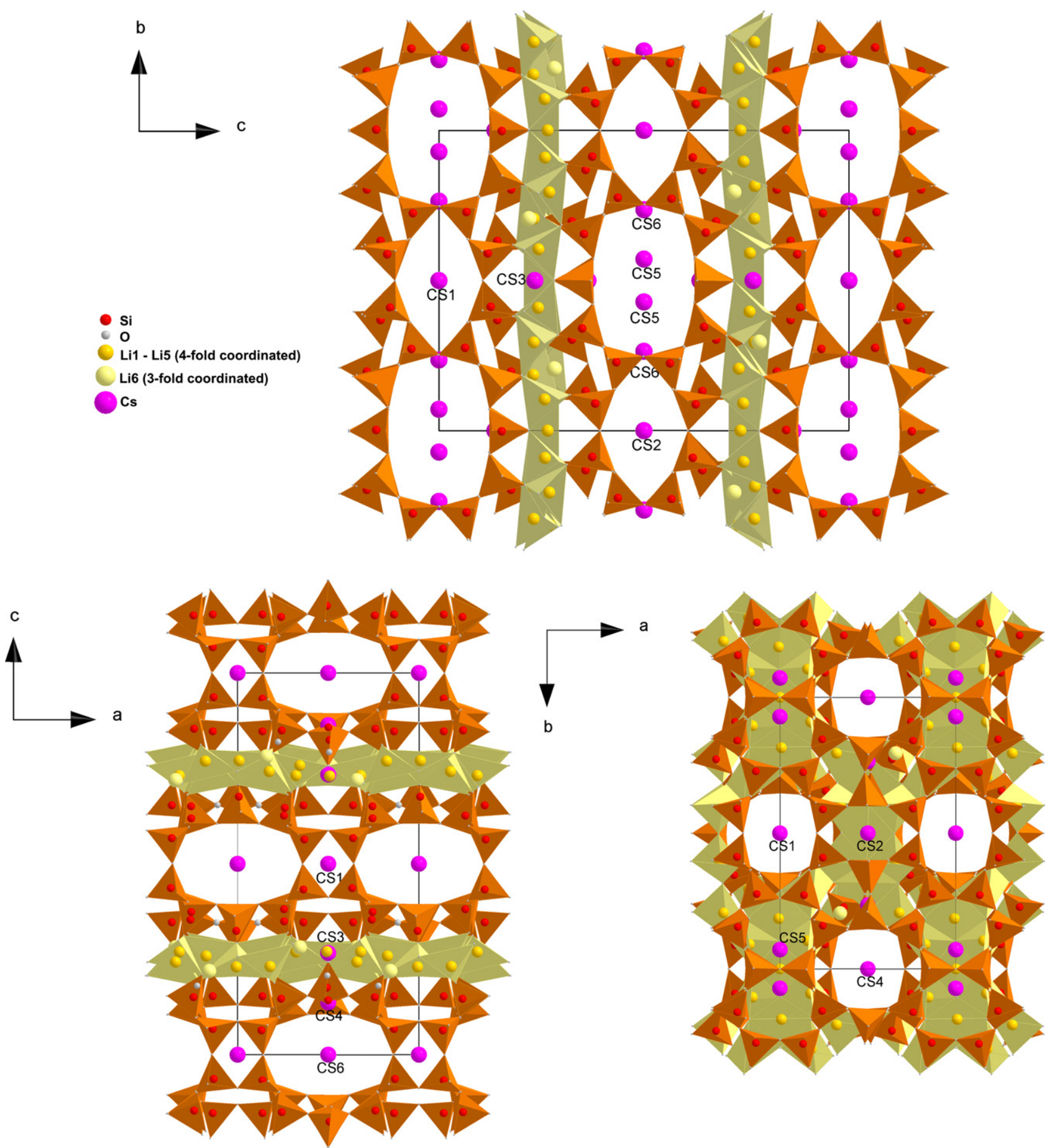

Fig. 4. Distribution of extra-framework Cs cations in the structure of dehydrated RUB-29 at 473 K, projected along $\boldsymbol{a}$ (a: top), $\boldsymbol{b}$ (b: left), and $\boldsymbol{c}$ (c: right). The framework is presented by $\left[\mathrm{LiO}_{4}\right]$ - and $\left[\mathrm{SiO}_{4}\right]$-tetrahedra in bright and dark tone, respectively. 

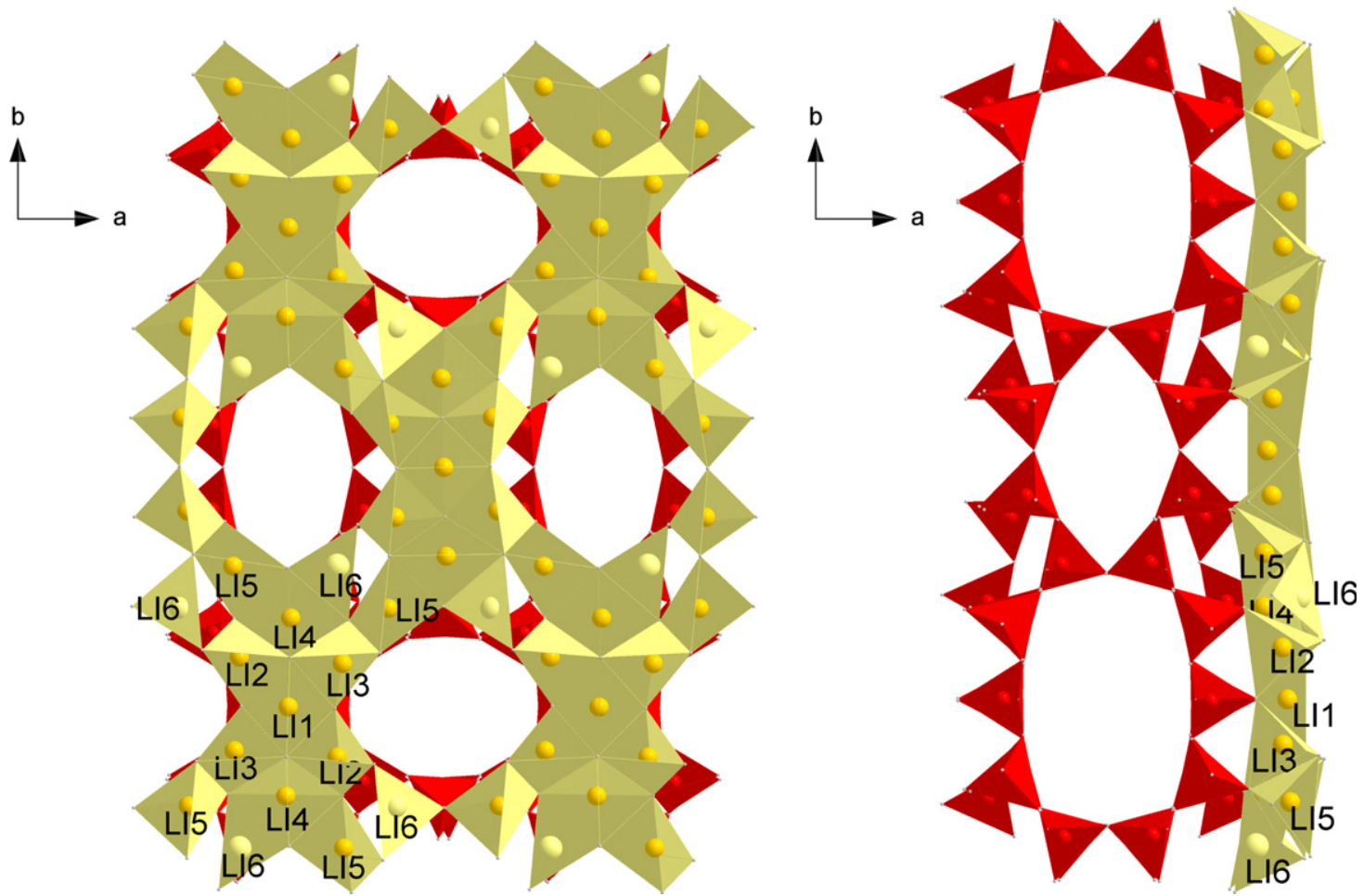

Fig. 5. Distribution of $\mathrm{Li}$ cations within a $\mathrm{Li}_{2} \mathrm{O}$-layer stacked above a $\mathrm{SiO}_{2}$-layer. The layer-like network of $\mathrm{Li}$ sites provides short pathways for $\mathrm{Li}$ conduction via hopping distances of $\sim 2.5 \AA$.

found at the site Cs7. On the other hand, the sites Cs4, Cs5, and Cs6 can be occupied either by Cs alone, or by both Cs and $\mathrm{Li}$. The latter case was not necessary to be concerned, as the final Rietveld calculation with respect to the former case agreed with an idealized structural formula of $\mathrm{Cs}_{14} \mathrm{Li}_{42} \mathrm{Si}_{72} \mathrm{O}_{172}$ for water-free RUB-29 within the standard deviations of occupancy parameter. The atomic parameters of both HT-d-RUB-29_473 K and $\_673 \mathrm{~K}$ resulting from neutron data are given in Tables 2 and 3 , respectively. The good fit at both temperatures is presented in Figs. 6 and 7. Selected interatomic distances for framework and non-framework constituents are supplied as supporting materials accompanying this report.

\subsection{AC impedance spectroscopy (IS)}

The plot of the real $\left(Z^{\prime}\right)$ versus the imaginary part $\left(Z^{\prime \prime}\right)$ of the impedance $Z^{*}(\omega)$ (Argand plot) shows a semicircle and a low-frequency tail (Fig. 8), which is typical for ionic conductors [30]. This is seen most clearly for the data at 773 and $873 \mathrm{~K}$. The semicircle is caused by at least one ionic relaxation mode [30], and a decreasing diameter of the semicircle with increasing temperature indicates a thermally activated process. In accordance with reports on the ionic conductivity of zeolites [8-10], the data obtained were further analyzed by means of the spectral plot of the imaginary part of the modulus $M^{\prime \prime}\left(=2 \pi v C_{0} Z^{\prime \prime}, v\right.$ : measuring frequency, $C_{0}$ : capacitance of the empty capacitor) to overemphasize the high frequency (HF) part of the spectra by a factor of $2 \pi \nu C_{0}$ [8]. Consequently, the modulus spectra allow ready visualization of relaxation processes, especially at high frequencies, which might be hidden in the Argand plot. The modulus-plot resulting from the first heating run gave rise to three maxima, all having almost identical intensities. The resonance frequency, $v_{\text {res }}$, the frequency at the maximum of $M^{\prime \prime}$, is shifted towards higher frequencies with increasing temperature for all peaks. This was analyzed by means of an Arrhenius plot (Fig. 9) and the activation energies, $E_{\mathrm{A}}$, of the corresponding processes determined using the Arrhenius relation

$\ln \left(Y^{\prime}\left(v_{\text {res }}\right) \cdot T\right)=A_{0}+E_{\mathrm{A}} / k_{\mathrm{B}} T$

$A_{0}$ is a pre-exponential factor that depends on the charge and number of the mobile species, its on-site oscillation frequency, and on the hopping distance [30,31]. The complex admittance (conductance) $Y^{*}(v)$ is a value of the complex specific conductivity $\sigma^{*}(v)$ scaled by the sample geometry $d / A$ (thickness $d$ and electrode area $A$ ). As can be seen in Fig. 9, the Arrhenius plot of the first heating run shows two activation energies of 102 and $233 \mathrm{~kJ} / \mathrm{mol}$ for the lower frequency (LF) relaxation processes. These LF processes were shifted towards higher frequencies and accompanied by a significant decrease in their activation energies $(74$ and $110 \mathrm{~kJ} / \mathrm{mol}$ ) in the second heating run. The first run resulted in $E_{\mathrm{A}} \approx 85 \mathrm{~kJ} / \mathrm{mol}$ for the middle frequency (MF) process, whereas this completely disappeared in the second heating run. Thus, these processes can be considered as interparticle relaxation processes, i.e. ionic conductivity passing through the grain boundaries. As mentioned 
Table 2

Fractional atomic coordinates, occupancies, and isotropic displacement parameters $\left(U_{\text {iso }}\right)$ of a high-temperature form of dehydrated RUB-29 at $473 \mathrm{~K}$, based on Rietveld analysis with high-resolution neutron powder diffraction data

\begin{tabular}{|c|c|c|c|c|c|c|}
\hline Site & Atom & $x$ & $y$ & $z$ & Occupancy & $100 * U_{\text {iso }}\left[\AA^{2}\right]$ \\
\hline Sil & $\mathrm{Si}$ & $0.3631(6)$ & $0.4977(9)$ & $-0.3468(3)$ & 1 & $1.12(6)$ \\
\hline $\mathrm{Si} 2$ & $\mathrm{Si}$ & $-0.2440(10)$ & $0.4099(7)$ & $-0.1189(5)$ & 1 & $1.12(6)$ \\
\hline Si3 & $\mathrm{Si}$ & $0.1368(10)$ & $0.2722(7)$ & $0.0672(6)$ & 1 & $1.12(6)$ \\
\hline $\mathrm{Si} 5$ & $\mathrm{Si}$ & $0.2601(10)$ & $0.3450(7)$ & $0.3536(5)$ & 1 & $1.12(6)$ \\
\hline $\mathrm{Si} 6$ & $\mathrm{Si}$ & $-0.2444(11)$ & $0.5878(8)$ & $-0.1262(4)$ & 1 & $1.12(6)$ \\
\hline $\mathrm{Si} 7$ & $\mathrm{Si}$ & $0.2563(10)$ & $0.6593(7)$ & $0.3493(5)$ & 1 & $1.12(6)$ \\
\hline $\mathrm{O} 1$ & $\mathrm{O}$ & $0.3494(5)$ & $0.4972(9)$ & $0.2811(2)$ & 1 & $1.35(5)$ \\
\hline $\mathrm{O} 2$ & $\mathrm{O}$ & $-0.0015(11)$ & $0.2601(3)$ & $0.0877(2)$ & 1 & $1.35(5)$ \\
\hline $\mathrm{O} 3$ & $\mathrm{O}$ & $-0.0026(12)$ & $0.2899(3)$ & $0.2575(2)$ & 1 & $1.35(5)$ \\
\hline $\mathrm{O} 4$ & $\mathrm{O}$ & $-0.2088(4)$ & $0.4996(9)$ & $-0.1070(2)$ & 1 & $1.35(5)$ \\
\hline $\mathrm{O} 5$ & $\mathrm{O}$ & $-0.2235(8)$ & $0.3807(6)$ & $-0.1805(4)$ & 1 & $1.35(5)$ \\
\hline O6 & $\mathrm{O}$ & $0.0172(7)$ & $0.2248(3)$ & $0.3638(3)$ & 1 & $1.35(5)$ \\
\hline $\mathrm{O} 12$ & $\mathrm{O}$ & 0 & 0 & $0.1295(3)$ & 1 & $1.35(5)$ \\
\hline $\mathrm{O} 13$ & $\mathrm{O}$ & $0.3252(8)$ & $0.3151(6)$ & $0.2989(3)$ & 1 & $1.35(5)$ \\
\hline $\mathrm{O} 14$ & $\mathrm{O}$ & $-0.3820(9)$ & $0.5994(8)$ & $-0.1065(6)$ & 1 & $1.35(5)$ \\
\hline O15 & $\mathrm{O}$ & $0.3052(7)$ & $0.6807(6)$ & $0.2902(4)$ & 1 & $1.35(5)$ \\
\hline $\mathrm{O} 16$ & $\mathrm{O}$ & $-0.1649(10)$ & $0.3652(6)$ & $0.0770(5)$ & 1 & $1.35(5)$ \\
\hline $\mathrm{O} 17$ & $\mathrm{O}$ & $0.1101(8)$ & $0.6513(6)$ & $0.3462(5)$ & 1 & $1.35(5)$ \\
\hline $\mathrm{O} 18$ & $\mathrm{O}$ & $-0.1701(10)$ & $0.3628(7)$ & $-0.0699(5)$ & 1 & $1.35(5)$ \\
\hline O19 & $\mathrm{O}$ & $0.1169(8)$ & $0.3583(6)$ & $0.3458(5)$ & 1 & $1.35(5)$ \\
\hline $\mathrm{O} 20$ & $\mathrm{O}$ & $0.2975(10)$ & $0.4285(5)$ & $0.3774(5)$ & 1 & $1.35(5)$ \\
\hline $\mathrm{O} 21$ & $\mathrm{O}$ & $-0.4946(12)$ & $0.6033(3)$ & $-0.2072(2)$ & 1 & $1.35(5)$ \\
\hline $\mathrm{O} 22$ & $\mathrm{O}$ & $0.3115(10)$ & $0.5795(6)$ & $0.3753(5)$ & 1 & $1.35(5)$ \\
\hline Li1 & $\mathrm{Li}$ & 0 & 0 & $0.7353(7)$ & $1.00(4)$ & $0.6(4)$ \\
\hline Cs4 & Cs & 0 & 0.5 & $0.3624(13)$ & $0.41(3)$ & $9(2)$ \\
\hline Cs5 & Cs & 0 & $0.0710(15)$ & 0 & $0.48(4)$ & $10(2)$ \\
\hline Cs6 & Cs & 0.5 & $0.7650(14)$ & 0 & $0.57(4)$ & $12(2)$ \\
\hline
\end{tabular}

The final Rietveld-refinement resulted in overall discrepancy indices: $w R_{p}=0.0293$ and $\chi^{2}=2.867\left[w R_{p}=\left(M / \Sigma w I_{o}^{2}\right)^{0.5}\right.$ with $M=\Sigma w\left(I_{o}-I_{c}\right)^{2}$; $\chi^{2}=M /(N-P)$, where $N$ is the number of observations $(=3277)$, and $P$ the number of free variables $\left.(=155)\right]$.

above, for the MF process, the possible influence of molecular water and/or moisture is excluded by the careful dehydration of the material in vacuum followed by preparation of the pellet in an argon glove box. Above $483 \mathrm{~K}$, HF processes were not detectable because of shifting of the frequency out of the measurable frequency window. The corresponding $E_{\mathrm{A}}$ determined in a temperature range of $373-483 \mathrm{~K}$ from the first run is $54 \mathrm{~kJ} / \mathrm{mol}$. In contrast to the other, LF and MF, processes, the resonance frequency of this process and its $E_{\mathrm{A}}$ were almost constant in the second heating run $(51 \mathrm{~kJ} / \mathrm{mol} \cong 0.53 \mathrm{eV})$. This suggests that the process is caused by intraparticle relaxation process, i.e. a bulk process.
The overall DC conductivity $\sigma$ for dehydrated RUB-29 was calculated from the low frequency intercept of the impedance plots (i.e. the diameter of semicircle) [32]. They lie between $2 \times 10^{-5}$ and $6 \times 10^{-5} \mathrm{~S} \mathrm{~cm}^{-1}$ at $873 \mathrm{~K}$, resulting from all runs of IS measurements performed at two laboratories at RWTH and LMU.

\section{Discussion}

The framework of the original structure of RUB-29 (Fig. 1; [1,6]) displays eight different sites for Li cations, which could be classified in three groups: each unit cell 
Table 3

Fractional atomic coordinates, occupancies and isotropic displacement parameters $\left(U_{\text {iso }}\right)$ of a high-temperature form of dehydrated RUB-29 at $673 \mathrm{~K}$, based on Rietveld analysis with high-resolution neutron powder diffraction data

\begin{tabular}{|c|c|c|c|c|c|c|}
\hline Site & Atom & $x$ & $y$ & $z$ & Occupancy & $100 * U_{\text {iso }}\left[\AA^{2}\right]$ \\
\hline Sil & $\mathrm{Si}$ & $0.3624(6)$ & $0.4984(11)$ & $-0.3462(3)$ & 1 & $1.64(7)$ \\
\hline $\mathrm{Si} 2$ & $\mathrm{Si}$ & $-0.2474(12)$ & $0.4093(9)$ & $-0.1194(5)$ & 1 & $1.64(7)$ \\
\hline $\mathrm{Si} 3$ & $\mathrm{Si}$ & $0.1377(13)$ & $0.2733(8)$ & $0.0654(6)$ & 1 & $1.64(7)$ \\
\hline $\mathrm{Si} 4$ & $\mathrm{Si}$ & $0.0061(13)$ & $0.3042(4)$ & $0.3249(3)$ & 1 & $1.64(7)$ \\
\hline $\mathrm{Si} 5$ & $\mathrm{Si}$ & $0.2565(13)$ & $0.3438(8)$ & $0.3533(5)$ & 1 & $1.64(7)$ \\
\hline $\mathrm{Si} 6$ & $\mathrm{Si}$ & $-0.2458(12)$ & $0.5874(9)$ & $-0.1263(4)$ & 1 & $1.64(7)$ \\
\hline $\mathrm{Si} 7$ & $\mathrm{Si}$ & $0.2556(12)$ & $0.6565(9)$ & $0.3492(5)$ & 1 & $1.64(7)$ \\
\hline $\mathrm{Si} 8$ & $\mathrm{Si}$ & $-0.4984(16)$ & $0.6331(4)$ & $-0.1433(3)$ & 1 & $1.64(7)$ \\
\hline $\mathrm{Si} 9$ & $\mathrm{Si}$ & $-0.1328(12)$ & $0.2773(8)$ & $0.0623(6)$ & 1 & $1.64(7)$ \\
\hline $\mathrm{O} 1$ & $\mathrm{O}$ & $0.3502(5)$ & $0.4969(11)$ & $0.2811(2)$ & 1 & $2.47(5)$ \\
\hline $\mathrm{O} 2$ & $\mathrm{O}$ & $0.0002(13)$ & $0.2620(3)$ & $0.0839(2)$ & 1 & $2.47(5)$ \\
\hline $\mathrm{O} 3$ & $\mathrm{O}$ & $-0.0013(15)$ & $0.2885(3)$ & $0.2586(3)$ & 1 & $2.47(5)$ \\
\hline $\mathrm{O} 4$ & $\mathrm{O}$ & $-0.2067(5)$ & $0.4989(10)$ & $-0.1066(2)$ & 1 & $2.47(5)$ \\
\hline O5 & $\mathrm{O}$ & $-0.2230(9)$ & $0.3829(8)$ & $-0.1812(5)$ & 1 & $2.47(5)$ \\
\hline O6 & $\mathrm{O}$ & $0.0157(9)$ & $0.2246(3)$ & $0.3626(3)$ & 1 & $2.47(5)$ \\
\hline O7 & $\mathrm{O}$ & $0.2788(13)$ & $0.2773(8)$ & $0.4009(6)$ & 1 & $2.47(5)$ \\
\hline $\mathrm{O} 8$ & $\mathrm{O}$ & $0.2242(13)$ & $0.2173(8)$ & $0.0978(6)$ & 1 & $2.47(5)$ \\
\hline O9 & $\mathrm{O}$ & $-0.2024(9)$ & $0.6133(7)$ & $-0.1877(5)$ & 1 & $2.47(5)$ \\
\hline $\mathrm{O} 10$ & $\mathrm{O}$ & $-0.1476(5)$ & $0.2552(3)$ & $-0.0014(6)$ & 1 & $2.47(5)$ \\
\hline O11 & $\mathrm{O}$ & $-0.3873(12)$ & $0.4009(10)$ & $-0.1079(7)$ & 1 & $2.47(5)$ \\
\hline $\mathrm{O} 12$ & $\mathrm{O}$ & 0 & 0 & $0.1290(4)$ & 1 & $2.47(5)$ \\
\hline O13 & $\mathrm{O}$ & $0.3182(13)$ & $0.3138(7)$ & $0.2980(4)$ & 1 & $2.47(5)$ \\
\hline O14 & $\mathrm{O}$ & $-0.3818(11)$ & $0.5980(10)$ & $-0.1070(7)$ & 1 & $2.47(5)$ \\
\hline O15 & $\mathrm{O}$ & $0.3095(12)$ & $0.6793(7)$ & $0.2900(4)$ & 1 & $2.47(5)$ \\
\hline O16 & $\mathrm{O}$ & $-0.1658(12)$ & $0.3645(7)$ & $0.0793(5)$ & 1 & $2.47(5)$ \\
\hline O17 & $\mathrm{O}$ & $0.1098(11)$ & $0.6524(8)$ & $0.3466(6)$ & 1 & $2.47(5)$ \\
\hline $\mathrm{O} 18$ & $\mathrm{O}$ & $-0.1738(11)$ & $0.3633(8)$ & $-0.0705(5)$ & 1 & $2.47(5)$ \\
\hline O19 & $\mathrm{O}$ & $0.1139(11)$ & $0.3566(8)$ & $0.3488(7)$ & 1 & $2.47(5)$ \\
\hline $\mathrm{O} 20$ & $\mathrm{O}$ & $0.3004(15)$ & $0.4257(8)$ & $0.3768(7)$ & 1 & $2.47(5)$ \\
\hline $\mathrm{O} 21$ & $\mathrm{O}$ & $-0.4936(14)$ & $0.6014(3)$ & $-0.2073(2)$ & 1 & $2.47(5)$ \\
\hline $\mathrm{O} 22$ & $\mathrm{O}$ & $0.3053(15)$ & $0.5773(8)$ & $0.3752(7)$ & 1 & $2.47(5)$ \\
\hline Li1 & $\mathrm{Li}$ & 0 & 0 & $0.7352(8)$ & $1.00(5)$ & $1.9(4)$ \\
\hline Li2 & $\mathrm{Li}$ & $0.3448(20)$ & $0.3914(13)$ & $0.2429(10)$ & $0.87(8)$ & $1.9(4)$ \\
\hline Li3 & $\mathrm{Li}$ & $0.3246(20)$ & $0.5924(12)$ & $0.2439(8)$ & $1.00(8)$ & $1.9(4)$ \\
\hline Li4 & $\mathrm{Li}$ & $0.0018(22)$ & $0.1808(9)$ & $0.2317(7)$ & $0.81(3)$ & $1.9(4)$ \\
\hline Li5 & $\mathrm{Li}$ & $-0.1756(18)$ & $0.7040(11)$ & $-0.2326(10)$ & $1.00(8)$ & $1.9(4)$ \\
\hline Li6 & $\mathrm{Li}$ & $-0.1489(20)$ & $0.2916(11)$ & $-0.2166(12)$ & $1.00(7)$ & $1.9(4)$ \\
\hline Cs1 & Cs & 0 & 0.5 & 0 & $1.00(4)$ & $3.7(8)$ \\
\hline $\mathrm{Cs} 2$ & Cs & 0 & 0 & 0.5 & $1.00(7)$ & $14(2)$ \\
\hline $\mathrm{Cs} 3$ & $\mathrm{Cs}$ & 0 & 0.5 & $0.7683(7)$ & $1.00(6)$ & $15(1)$ \\
\hline $\mathrm{Cs} 4$ & $\mathrm{Cs}$ & 0 & 0.5 & $0.3700(2)$ & $0.32(4)$ & $9(3)$ \\
\hline Cs 5 & Cs & 0 & $0.0579(20)$ & 0 & $0.51(6)$ & $20(3)$ \\
\hline Cs6 & $\mathrm{Cs}$ & 0.5 & $0.7556(16)$ & 0 & $0.69(5)$ & $18(2)$ \\
\hline
\end{tabular}

The final Rietveld-refinement resulted in overall discrepancy indices $w R_{p}=0.0288$ and $\chi^{2}=2.244(P=153 ; N=3250)$.

contains $18 \mathrm{Li}$ at four different framework Li sites, while 16 non-framework $\mathrm{Li}$ (Li4 and Li5 in Fig. 1) are present at two different sites of $\left[\mathrm{LiO}_{3}\right]$-moieties in the immediate vicinity to the framework Li sites. Both groups of Li sites build up the $\mathrm{LiO}_{2}$-layers, located in-between LLBU's of $\left[\mathrm{SiO}_{4}\right]$ tetrahedra. The third group of Li sites is located within 8-and 10MR-channels where eight $\mathrm{Li}$ cations are either 4fold coordinated with two framework oxygens and two water molecules ( $\mathrm{Li} 7$ in Fig. 1), or 3-fold coordinated with three framework oxygens (Li8 in Fig. 1). HT-d-RUB-29, on the other hand, contains five unique $\left[\mathrm{LiO}_{4}\right]$-moieties (i.e. the sites $\mathrm{Li} 1, \mathrm{Li} 2, \mathrm{Li} 3, \mathrm{Li} 4$, and $\mathrm{Li} 5$ ) and one $\left[\mathrm{LiO}_{3}\right]$ moiety (the site $\mathrm{Li} 6$ ), which build the $\mathrm{LiO}_{2}$-layers (Fig. 5).
Therefore, from the point of view of crystal chemistry, it is difficult to attribute the sites among Li1-Li5 to extraframework Li. All of $42 \mathrm{Li}$ cations present in the unit cell are exclusively located within $\mathrm{LiO}_{2}$-layers, where they are statistically distributed at 44 interstitials.

More importantly, the refined structure models of HT-d-RUB-29_473 K and $673 \mathrm{~K}$ indicate that eight non-framework Li cations per unit cell found in as-synthesized RUB-29 must migrate from the large pore space into the $\mathrm{Li}_{2} \mathrm{O}$-layers after the water loss. In the absence of water molecules, $\mathrm{Cs}$ and Li cations can satisfy their coordination requirements closer to the negatively charged $\left[(\mathrm{Li}, \mathrm{Si}) \mathrm{O}_{4}\right]$-framework. Of course, the smaller $\mathrm{Li}$ cations 


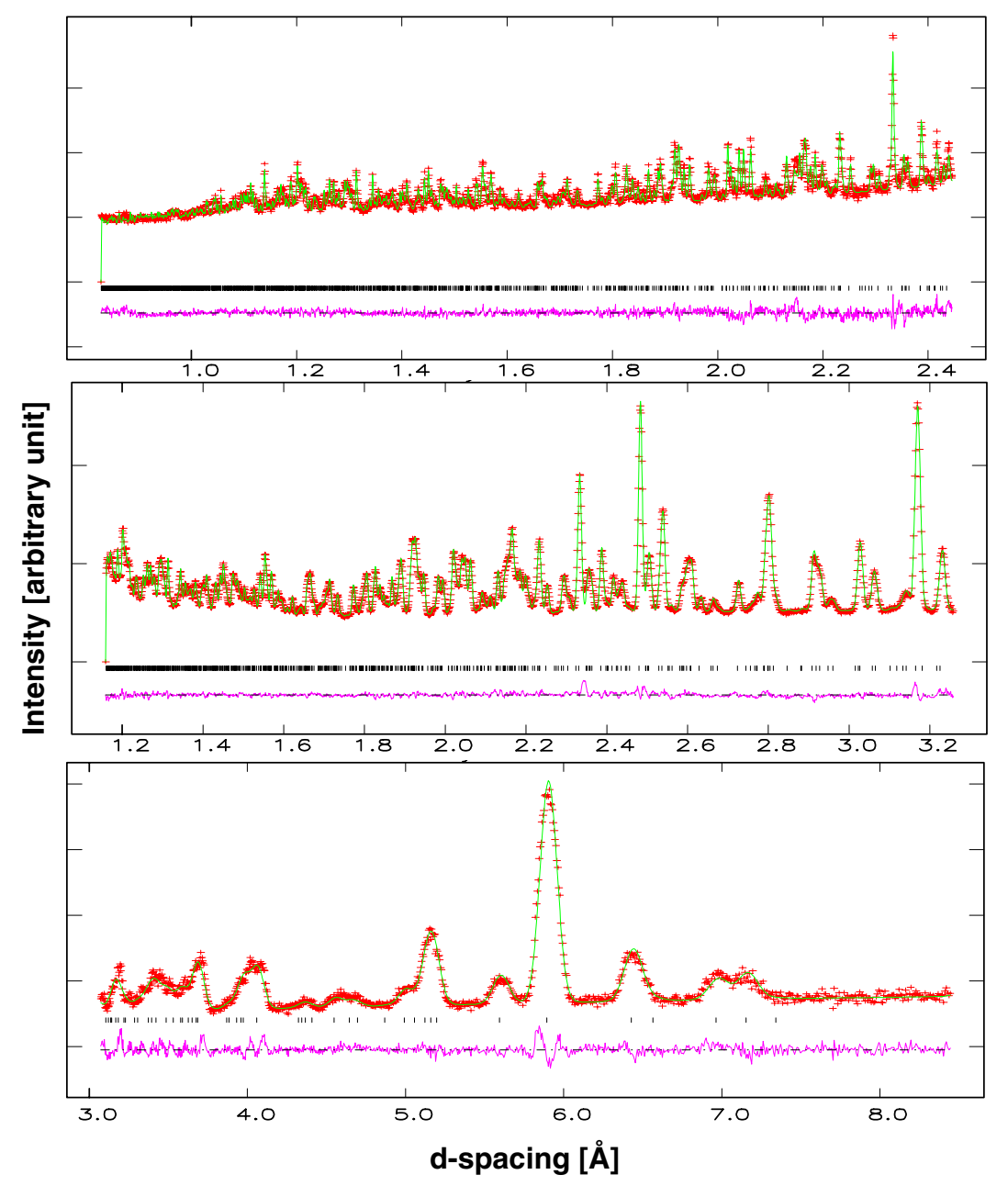

Fig. 6. Observed (crosses) and calculated (line) high-resolution neutron powder diffraction pattern (HRNPD) of dehydrated RUB-29 at 473 K. The bars and the line at the bottom represent reflection positions and difference between observed and calculated HRNPD pattern, respectively. The data sets were collected on three different detectors (from top to bottom: $154^{\circ}, 90^{\circ}$, and $30^{\circ}$ detector).

can more readily migrate into the densely packed $\mathrm{Li}_{2} \mathrm{O}-$ layers than large Cs cations.

The site Cs7 in the structure of hydrated RUB-29 (assynthesized) was assigned to one for statistically disordered water molecules and Cs cations [1,6]. As mentioned in the previous section, however, the site Cs7 is occupied neither by Cs nor Li in HT-d-RUB-29_473 K and $673 \mathrm{~K}$. This is another indication that non-framework Li cations prefer to be within the $\mathrm{Li}_{2} \mathrm{O}$-layers when there is no zeolitic water. Moreover, the present study using HRNPD data combined with XSD clearly show that, before water loss, this site must have been preferentially occupied by water molecules and not by Cs cations, because the refined models of dehydrated RUB-29 show no evidence of Cs at the Cs7 site. Furthermore, the short interatomic distance 2.8(4) $\AA$ from Cs7 to Si5 supports the assumption of water molecules present at this site prior to water loss. There are no remarkable changes in the occupancies for all $\mathrm{Li}$ and $\mathrm{Cs}$ sites between 473 and $673 \mathrm{~K}$ (Tables 2 and 3). This is consistent with the small number of empty sites remaining in the $\mathrm{Li}_{2} \mathrm{O}$-layers for the $\mathrm{Li}$ conduction and the lack of suitable sites for $\mathrm{Li}$ in the large pores once water molecules are no more present.

The open framework lithosilicate RUB-29 contains unusual 3-membered rings being stable up to $1073 \mathrm{~K}$. The high amount of $\mathrm{Li}(42 \mathrm{Li}$ atoms per unit cell), resident in both framework and extra-framework parts of the structure, provides a variety of possible pathways for mobile $\mathrm{Li}^{+}$, and this zeolite-like material represents a new type of solid-state Li-cationic conductor. The refined crystal structure elucidated the reason for the decrease of favourable pathways in RUB-29 after the water loss: the migration of non-framework Li cations from the large pore space into the $\mathrm{Li}_{2} \mathrm{O}$-layers leads to a decrease in the number of empty sites available for $\mathrm{Li}$ hopping within the $\mathrm{Li}_{2} \mathrm{O}$-layers, i.e. a decrease of favourable pathways. This is the structural basis for the barely improved conductivity, determined by AC impedance with dehydrated samples of RUB-29 above $473 \mathrm{~K}$

A conductivity value of $\sim 10^{-6} \mathrm{~S} \mathrm{~cm}^{-1}$ at $473 \mathrm{~K}$ was estimated in the previous study using variable-temperature ${ }^{7}$ Li MAS NMR [1]. The same value for the bulk ionic 

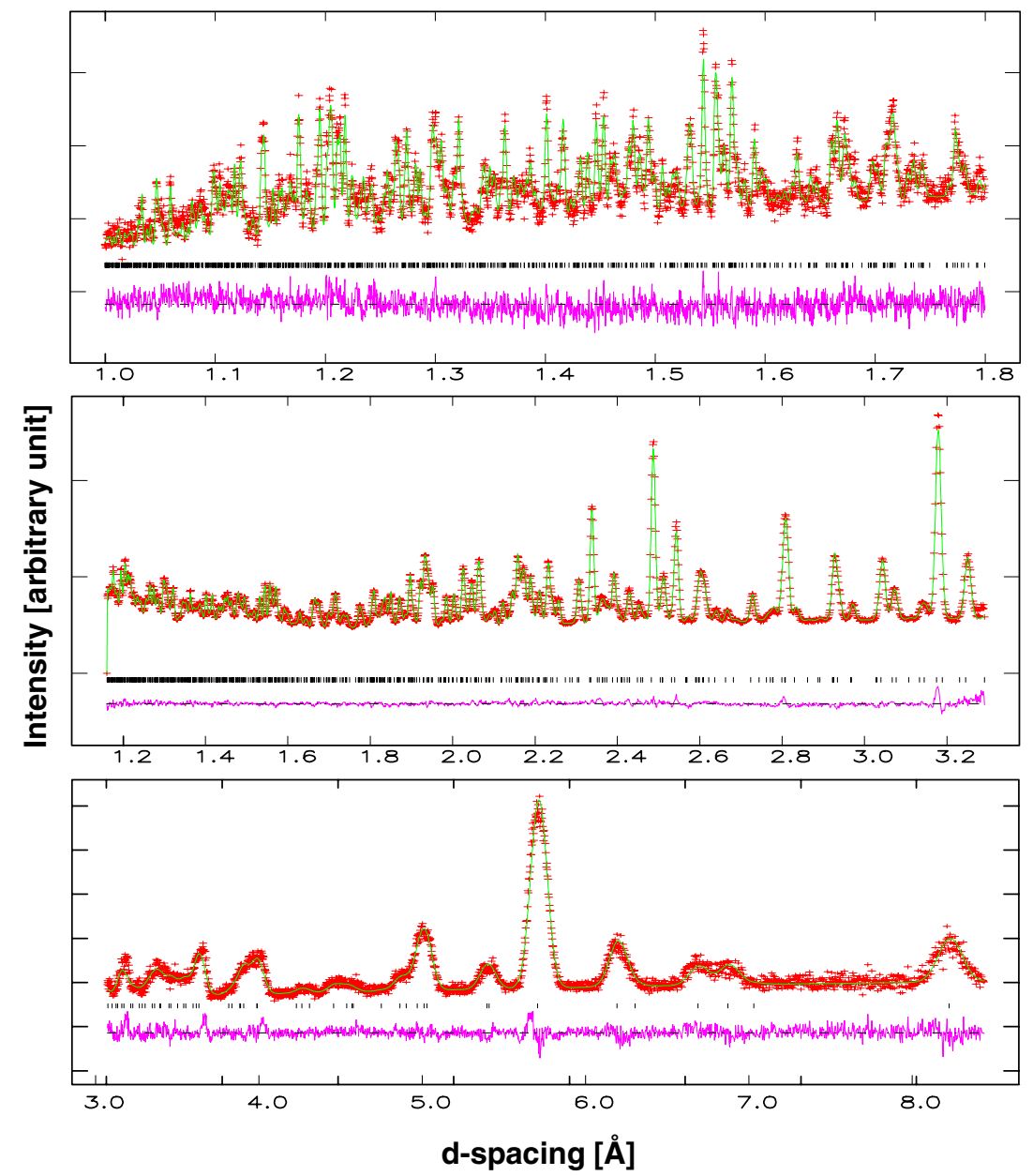

Fig. 7. Observed (crosses) and calculated (line) high-resolution neutron powder diffraction pattern (HRNPD) of dehydrated RUB-29 at 673 K.

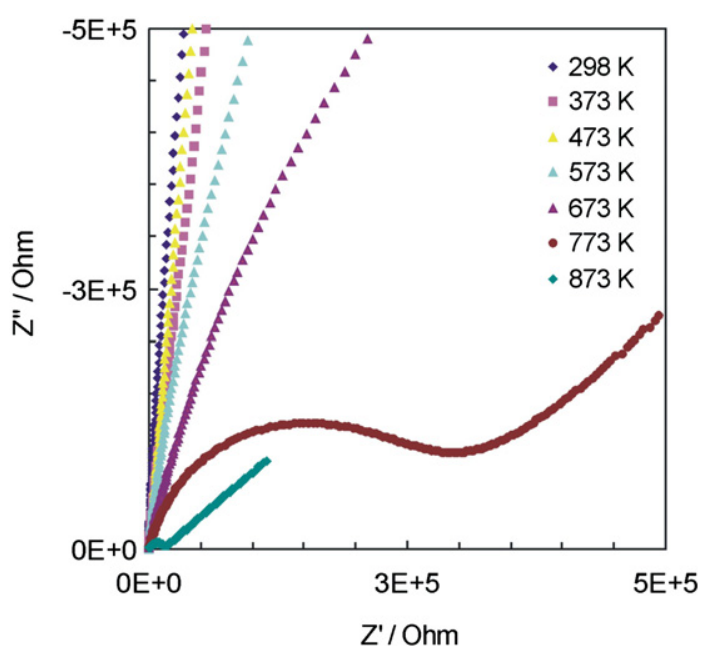

Fig. 8. Complex impedance plane plots obtained while cooling a dehydrated sample of RUB-29 from 873 down to $298 \mathrm{~K}$ (from left to right). Decrease in the size of the semicircles with increasing temperature is due to the bulk charge transfer, which needs to overcome an energy barrier.

conductivity was evaluated, however, at a higher temperature $(653 \mathrm{~K})$ from $\mathrm{AC}$ impedance in this study. Note that all possible charge transports not only by $\mathrm{Li}$, but also by Cs cations might have contributed the bulk conductivity value estimated from the IS spectra. Without further complementary experiments, however, it is not possible to assign this HF relaxation process with certainty to particular site-exchanging ionic species of RUB-29. This may be one reason for the overall conductivity values evaluated with impedance spectra being smaller than those previously estimated with ${ }^{7} \mathrm{Li}$ MAS NMR spectra, as the latter arise exclusively from the mobility of one species, i.e. ${ }^{7} \mathrm{Li}$. In this context, relaxation modes due to local motions and/or fast conduction of framework Li cations could be outside the frequency range of $\mathrm{AC}$ impedance spectroscopy technique $\left(>10^{7} \mathrm{~Hz}\right)$.

A bulk conductivity of $6 \times 10^{-5} \mathrm{~S} \mathrm{~cm}^{-1}$ of RUB-29 determined by IS at $873 \mathrm{~K}$ is lower than that of Li-analcime $\left(5.4 \times 10^{-4} \mathrm{~S} \mathrm{~cm}^{-1}\right.$ at $\left.873 \mathrm{~K}\right)$ known as the best Li-ionic conductor among zeolites, so far $[33,34]$. In addition, the bulk conductivity of RUB-29 is far from the superionic conductivity value of $\sim 10^{-2} \mathrm{~S} \mathrm{~cm}^{-1}$ at room temperature. Nonetheless, an activation energy of $0.53 \mathrm{eV}$ calculated for the HF relaxation in RUB-29 is at the lowest region of values reported for ionic conductivity in zeolites 


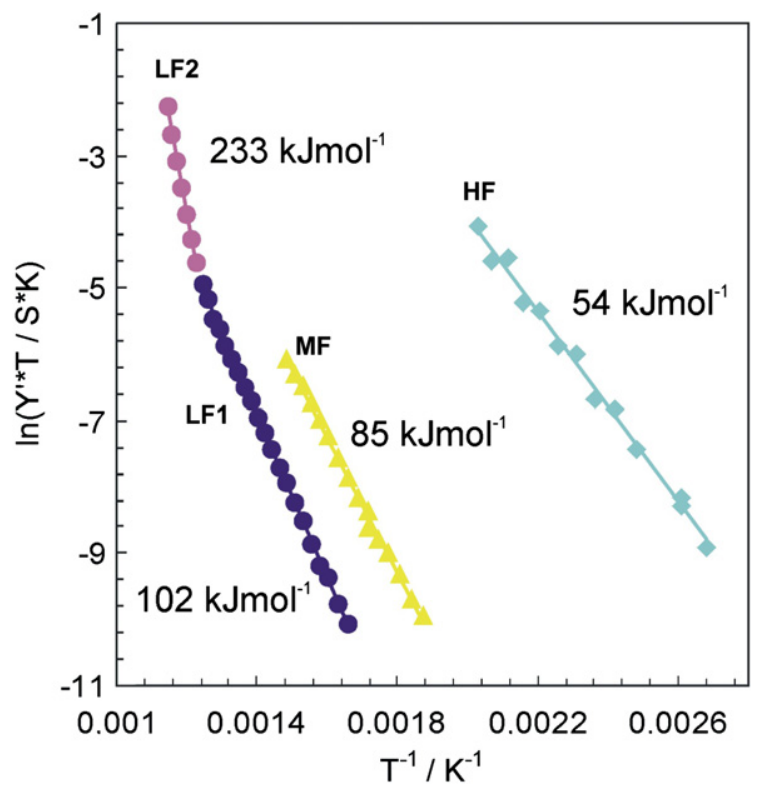

Fig. 9. Arrhenius plots for dehydrated RUB-29 obtained from the first heating run. To activate the high frequency (HF) relaxation process the system needs to overcome an energy barrier $\left(E_{\mathrm{A}}\right)$ of $54 \mathrm{~kJ} / \mathrm{mol}$ in a temperature range from 373 to $483 \mathrm{~K}$. From the second run, the $E_{\mathrm{A}}$ for the HF process showed only a small decrease from 54 down to $51 \mathrm{~kJ} / \mathrm{mol}$. This almost constant value of $E_{\mathrm{A}}$ from different experimental runs indicates a bulk relaxation process.

[8-10,33,34], and comparable to those for spinel- [35] and perovskite-type oxides [36], and for halides [37]. The low activation energy is indicative of the ease with which charge transfer occurs in RUB-29. This may trace back to the structural property providing short pathways for Li hopping. The present work indicates that the disposition and occupation of the non-framework cation sites are primary factors tuning the configuration the $\mathrm{Li}_{2} \mathrm{O}$-layers and, hence, they greatly influence the dynamic and static disorder of Li over the entire lattice. This insight will be implemented in developing RUB-29-type materials with high $\mathrm{Li}$ conductivity.

\section{Acknowledgments}

S.H.P. acknowledges financial support from Deutsche Forschungsgemeinschaft (DFG) via PA 1222/1-1. The collecting of XSD data has been executed via II-05-014 permitted by DESY, Germany. Dr. Elmar Schmidbauer has helped on conducting AC. IS measurements at Department of Earth and Environmental Sciences at LMU. J.B.P. is grateful for the continued support of the NSF through grants CHE-0221934 (Center for Environmental Molecular Sciences) and DMR-04-524444. The authors thank Dr. Hans Boysen and Prof. Friedrich Frey at LMU for helpful discussion and advice during the revision of this manuscript.

\section{Appendix A. Supplementary data}

Supplementary data associated with this article can be found, in the online version, at doi:10.1016/ j.micromeso.2007.03.040.

\section{References}

[1] S.-H. Park, J.B. Parise, H. Gies, H. Liu, C.P. Grey, B.H. Toby, J. Am. Chem. Soc. 122 (44) (2000) 11023-11024.

[2] S.-H. Park, P. Daniels, H. Gies, Micropor. Mesopor. Mater. 37 (2000) 129-143.

[3] S.-H. Park, H. Gies, B.H. Toby, J.B. Parise, Chem. Mater. 14 (2002) 3187-3196.

[4] S.-H. Park, H. Liu, M. Kleinsorge, C.P. Grey, B.H. Toby, J.B. Parise, Chem. Mater. 16 (2004) 2605-2614.

[5] S.-H. Park, H. Boysen, J.B. Parise, Acta Cryst. B 62 (2005) 42-51.

[6] S.-H. Park, J.B. Parise, H. Gies, Studies in Surface Science and Catalysis, vol. 135, Elsevier, 2001, Paper 09-0-05.

[7] F. Liebau, Micropor. Mesopor. Mater. 58 (2003) 15-72.

[8] U. Simon, M.E. Franke, Micropor. Mesopor. Mater. 41 (2000) 1-36.

[9] M.E. Franke, U. Simon, Solid State Ionics 118 (1999) 311-316.

[10] U. Simon, U. Flesch, J. Porous Mater. 6 (1999) 33-40.

[11] S.-H. Park, J.B. Parise, H. Gies, A. Hewat, Experimental report 5-22572, Institute Laue-Langevin, Grenoble, France, 2002.

[12] S.-H. Park, F. Frey, C. Paulmann, Abstract \#041-06, Annual meeting of DGK (Deutsche Gesellschaft für Kristallographie), March 5-8, 2007, Bremen, Germany.

[13] P.M. de Wolff, Acta Cryst. A 30 (1974) 777-785.

[14] M. Korekawa, Habilitation Thesis, Ludwig-Maximilians-Universität München, Germany, 1967.

[15] H. Jobic, J. Kräger, M. Bée, Phys. Rev. Lett. 82 (21) (1999) 4260 4263.

[16] H. Jobic, Phys. Chem. Chem. Phys. 1 (1999) 525-530.

[17] S.-H. Park, Experimental report 7-06-39, Institute Laue-Langevin, Grenoble, France, 2004.

[18] S.-H. Park, Experimental report 7-06-46, Institute Laue-Langevin, Grenoble, France, 2006.

[19] P. Norby, Mater. Sci. Forum 228-231 (1996) 147-152.

[20] S. Merlino, Eur. J. Mineral. 2 (1990) 809-817.

[21] T.S. Ercit, J. Van Velthuizen, Can. Mineral. 32 (1994) 855-863.

[22] M.J. Annen, M.E. Davis, J.B. Higgins, J.L. Schlenker, Mater. Res. Soc. Symp. Proc. 233 (1991) 245-253.

[23] C. Röhrig, H. Gies, B. Marler, Zeolites 14 (1994) 498-503.

[24] C. Röhrig, H. Gies, Angew. Chem. Int. Ed. Engl. 34 (1) (1995) 63-65.

[25] W.J. Kabsch, J. Appl. Cryst. 26 (1993) 795-800.

[26] M.A. Estermann, W. Steurer, Phase Transit. 67 (1996) 165-195.

[27] G.M. Sheldrick, SHELXTL, Siemens Analytical X-ray Instruments Inc., Madison, Wisconsin, USA, 1990.

[28] G.M. Sheldrick, SHELXL-97, University of Göttingen, Germany, 1997.

[29] A.C. Larson, R.B. Von Dreele, GENERAL STRUCTURAL ANALYSIS SYSTEM (GSAS), Los Alamos National Laboratory Report LAUR 86-748, Los Alamos National Laboratory, Los Alamos, NM, USA, 2000.

[30] J.R. Macdonald, Impedance Spectroscopy, Wiley, New York, 1987.

[31] M.J. Rice, W.L. Roth, J. Solid State Chem. 4 (1972) 294-310.

[32] Y.T. Tsai, D.H. Whitmore, Sold State Ionics 7 (1982) 129-139.

[33] G. Kelemen, W. Lortz, G. Schön, J. Mater. Sci. 24 (1989) 333-338.

[34] G. Kelemen, G. Schön, J. Mater. Sci. 27 (1992) 6036-6040.

[35] M. Nakayama, Y. Ishida, H. Ikuta, M. Wakihara, Solid State Ionics 117 (1999) 265-271.

[36] L. Sebastian, A.K. Shukla, J. Gopalakrishnan, Proc. Indian Acad. Sci. (Chem. Sci.) 113 (5-6) (2001) 427-433.

[37] R. Nagel, Th.W. Gross, H. Günther, H.D. Lutz, J. Solid State Chem. 165 (2002) 303-311. 